Abstracta Iranica Iranica

Revue bibliographique pour le domaine irano-aryen

Volume 23 | 2002

Comptes rendus des publications de $\mathbf{2 0 0 0}$

\title{
"Magic in Classical Persian Amatory Literature ». Iranian Studies, vol. 32, n 1 (1999), pp. 71-97.
}

\section{Marina Gaillard}

\section{(2) OpenEdition}

12 Journals

\section{Édition électronique}

URL : http://journals.openedition.org/abstractairanica/35842

DOI : 10.4000/abstractairanica.35842

ISSN : 1961-960X

Éditeur :

CNRS (UMR 7528 Mondes iraniens et indiens), Éditions de l'IFRI

\section{Édition imprimée}

Date de publication : 15 mai 2002

ISSN : 0240-8910

\section{Référence électronique}

Marina Gaillard, « "Magic in Classical Persian Amatory Literature ». Iranian Studies, vol. 32, n 1 (1999), pp. 71-97. », Abstracta Iranica [En ligne], Volume 23 | 2002, document 291, mis en ligne le 08 février

2010, consulté le 25 septembre 2020. URL : http://journals.openedition.org/abstractairanica/35842 ; DOI : https://doi.org/10.4000/abstractairanica.35842

Ce document a été généré automatiquement le 25 septembre 2020.

Tous droits réservés 


\title{
« Magic in Classical Persian Amatory Literature ». Iranian Studies, vol. 32, nº 1 (1999), pp. 71-97.
}

\author{
Marina Gaillard
}

1 L'étude porte sur les comparaisons imagées entre l'amour et la magie dans la littérature persane classique. L'A. recense plusieurs thèmes - comme l'aimé(e) considéré(e) en tant qu'être d'essence surnaturelle, le pouvoir magique du regard, le démon de l'amour -, et aborde également les métaphores magiques dans les textes mystiques.

Dans la première partie, l'A. relève les comparaisons entre l'aimée et la parī («fée », " péri »), retraçant brièvement l'évolution littéraire de cette dernière, ainsi que celle de la femme-sorcière (zan jādū, [sic, pour zan-e jādū]). À la recherche d'une description de parī, et confronté au silence des œuvres de la littérature classique sur le sujet, l'A. croit en trouver un exemple dans le roman populaire. Mais le passage qu'il cite, tiré du

Samak-e 'Ayyār, est fort malencontreux. Cette longue description est ainsi présentée : "The most elaborate and detailed physical description of a pari is found in the romance of Samak-i "Ayyar where the classical example of falling in love with a fairy is detailed ". Abusé par le nom de la princesse Māh-Parī, et malgré ses remarques sur les noms propres composés avec le terme parī, l'auteur a confondu avec une parì la fille du roi de Čĩn, la princesse parfaite, qui deviendra l'épouse de Hyoršīd-šāh. Ce prince est précisément l'un des rares héros à ne pas contracter de mariage avec une créature surnaturelle et à n'épouser que des princesses de haute lignée humaine. Le résumé, comme les réflexions qui suivent cet exemple (et la note 50) sont donc également faux puisque c'est la nourrice de la jeune fille, une sorcière, qui tend le piège au prince, l'attire jusqu'à la tente de Māh-Parī et provoque ainsi sa maladie amoureuse. L'A. semble n'avoir consulté ni les études relatives à ce récit, ni sa traduction. Curieusement, il note bien que la description donnée n'est autre que celle de la «beauté type ", mais il continue à voir une parī en la personne décrite, alors que quantité de 
descriptions similaires données par les récits, toutes concernant des princesses, amènent rapidement à constater que cette beauté correspond à celle du personnage type de la princesse (v. ouvrage cité in Abs. Ir., 11, n 912). Un autre exemple, tiré de l' Eskandar-nāme, n'est pas plus heureux: il n'est en effet pas significatif d'un « ensorcellement » spécifiquement produit par la reine pari Araqit sur Alexandre, mais traduit en termes courants la simple naissance du sentiment amoureux à la vue d'une exceptionnelle beauté ; l'effet produit sur Alexandre par la fille du roi du Yémen, par exemple, est rapporté dans les mêmes termes (éd. I. Afšār, Tehrān, B.T.N.K., 1343/1964, p. 112 ; on déplore que l'A. ne cite que d'après traduction). Sur d'autres points encore, certaines interprétations données sont également discutables. Ce vaste sujet demanderait à être reconsidéré de plus près.

INDEX

Thèmes : 11.1.1. Littérature persane classique

\section{AUTEURS}

MARINA GAILLARD

CNRS - Paris 